\title{
Impact of Baseline Steroids on Efficacy of Programmed Cell Death-1 and Programmed Death- Ligand 1 Blockade in Patients With Non-Small-Cell Lung Cancer
}

Citation for published version (APA):

Arbour, K. C., Mezquita, L., Long, N., Rizvi, H., Auclin, E., Ni, A., Martinez-Bernal, G., Ferrara, R., Lai, W. V., Hendriks, L. E. L., Sabari, J. K., Caramella, C., Plodkowski, A. J., Halpenny, D., Chaft, J. E., Planchard, D., Riely, G. J., Besse, B., \& Hellmann, M. D. (2018). Impact of Baseline Steroids on Efficacy of Programmed Cell Death-1 and Programmed Death-Ligand 1 Blockade in Patients With Non-Small-Cell Lung Cancer. Journal of Clinical Oncology, 36(28), 2872-2878. https://doi.org/10.1200/JCO.2018.79.0006

Document status and date:

Published: 01/10/2018

DOI:

10.1200/JCO.2018.79.0006

Document Version:

Publisher's PDF, also known as Version of record

Document license:

Taverne

Please check the document version of this publication:

- A submitted manuscript is the version of the article upon submission and before peer-review. There can be important differences between the submitted version and the official published version of record. People interested in the research are advised to contact the author for the final version of the publication, or visit the DOI to the publisher's website.

- The final author version and the galley proof are versions of the publication after peer review.

- The final published version features the final layout of the paper including the volume, issue and page numbers.

Link to publication

\footnotetext{
General rights rights.

- You may freely distribute the URL identifying the publication in the public portal. please follow below link for the End User Agreement:

www.umlib.nl/taverne-license

Take down policy

If you believe that this document breaches copyright please contact us at:

repository@maastrichtuniversity.nl

providing details and we will investigate your claim.
}

Copyright and moral rights for the publications made accessible in the public portal are retained by the authors and/or other copyright owners and it is a condition of accessing publications that users recognise and abide by the legal requirements associated with these

- Users may download and print one copy of any publication from the public portal for the purpose of private study or research.

- You may not further distribute the material or use it for any profit-making activity or commercial gain

If the publication is distributed under the terms of Article 25fa of the Dutch Copyright Act, indicated by the "Taverne" license above, 
Author affiliations and support information (if applicable) appear at the end of this article.

Published at jco.org on August 20, 2018. K.C.A. and L.M. contributed equally to this work

B.B. and M.D.H. contributed equally to this work.

Corresponding author: Matthew D. Hellmann, Memorial Sloan Kettering Cancer Center, 885 2nd Ave, New York, NY, 10017; e-mail: hellmanm@mskcc.org. (C) 2018 by American Society of Clinical Oncology

$0732-183 X / 18 / 3628 w-2872 w / \$ 20.00$

\section{Impact of Baseline Steroids on Efficacy of Programmed Cell Death-1 and Programmed Death-Ligand 1 Blockade in Patients With Non-Small-Cell Lung Cancer}

Kathryn C. Arbour, Laura Mezquita, Niamh Long, Hira Rizvi, Edouard Auclin, Andy Ni, Gala Martínez-Bernal, Roberto Ferrara, W. Victoria Lai, Lizza E.L. Hendriks, Joshua K. Sabari, Caroline Caramella, Andrew J. Plodkowski, Darragh Halpenny, Jamie E. Chaft, David Planchard, Gregory J. Riely, Benjamin Besse, and Matthew D. Hellmann

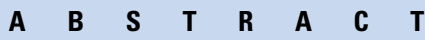

\section{Purpose}

Treatment with programmed cell death-1 or programmed death ligand 1 (PD-(L)1) inhibitors is now standard therapy for patients with lung cancer. The immunosuppressive effect of corticosteroids may reduce efficacy of PD-(L)1 blockade. On-treatment corticosteroids for treatment of immunerelated adverse events do not seem to affect efficacy, but the potential impact of baseline corticosteroids at the time of treatment initiation is unknown. Clinical trials typically excluded patients who received baseline corticosteroids, which led us to use real-world data to examine the effect of corticosteroids at treatment initiation.

\section{Methods}

We identified patients who were PD-(L)1-naïve with advanced non-small-cell lung cancer from two institutions-Memorial Sloan Kettering Cancer Center and Gustave Roussy Cancer Center-who were treated with single-agent PD-(L)1 blockade. Clinical and pharmacy records were reviewed to identify corticosteroid use at the time of beginning anti-PD-(L)1 therapy. We performed multivariable analyses using Cox proportional hazards regression model and logistic regression.

\section{Results}

Ninety $(14 \%)$ of 640 patients treated with single-agent PD-(L)1 blockade received corticosteroids of $\geq 10 \mathrm{mg}$ of prednisone equivalent daily at the start of the PD-(L)1 blockade. Common indications for corticosteroids were dyspnea (33\%), fatigue (21\%), and brain metastases (19\%). In both independent cohorts, Memorial Sloan Kettering Cancer Center $(n=455)$ and Gustave Roussy Cancer Center $(n=185)$, baseline corticosteroids were associated with decreased overall response rate, progression-free survival, and overall survival with $\mathrm{PD}-(\mathrm{L}) 1$ blockade. In a multivariable analysis of the pooled population, adjusting for smoking history, performance status, and history of brain metastases, baseline corticosteroids remained significantly associated with decreased progressionfree survival (hazard ratio, 1.3; $P=.03$ ), and overall survival (hazard ratio, 1.7; $P<.001$ ).

\section{Conclusion}

Baseline corticosteroid use of $\geq 10 \mathrm{mg}$ of prednisone equivalent was associated with poorer outcome in patients with non-small-cell lung cancer who were treated with PD-(L)1 blockade. Prudent use of corticosteroids at the time of initiating PD- $(\mathrm{L}) 1$ blockade is recommended.

\section{J Clin Oncol 36:2872-2878. (c) 2018 by American Society of Clinical Oncology}

\section{INTRODUCTION}

The development of immune checkpoint blockade (ICB) therapy has dramatically changed the treatment landscape for patients with cancer. ${ }^{1}$ For patients with advanced non-small-cell lung cancer (NSCLC), treatment with antiprogrammed cell death 1 (PD-1) or programmed death-ligand 1 (PD-L1) therapy (PD-(L) 1 blockade) is now a standard of care. ${ }^{2-4}$ As realworld clinical experience with ICB agents continues to grow, new questions have emerged regarding the treatment of patients that could not be answered in the initial groundbreaking clinical trials.

Corticosteroids are commonly used in patients with NSCLC to treat a variety of indications, 
including fatigue, dyspnea, decreased appetite, and symptomatic brain metastases. ${ }^{5-9}$ Given the immunosuppressive properties of corticosteroids and the potential effect on T-cell function, ${ }^{10}$ there is understandable concern that the use of these agents could decrease the efficacy of ICB. As a result, use of corticosteroids before the start of therapy has been a uniform exclusion criterion in clinical trials of ICB. It is perhaps surprising, but reassuring, to see emerging data that on-treatment corticosteroids used for the management of immune-related adverse events ${ }^{11}$ do not seem to negatively affect efficacy. ${ }^{12-15}$ Yet there are no data to date that evaluate whether corticosteroids at baseline affect the efficacy of ICB. We therefore evaluated the potential impact of systemic corticosteroids at the start of ICB on the efficacy of PD-(L)1 blockade in more than 600 patients who were treated at two independent cancer centers.

\section{METHODS}

\section{Patients}

Patients with advanced NSCLC who were treated with single-agent PD-(L)1 inhibitor (pembrolizumab, nivolumab, atezolizumab, or durvalumab) with treatment initiation between April 2011 to September 2017 were identified at Memorial Sloan Kettering Cancer (MSKCC; $\mathrm{n}=455$ ) and Gustave Roussy Cancer Center (GRCC; $\mathrm{n}=185$ ). Patients' records, including pharmacy records, were reviewed to determine if patients were documented as having received any oral or intravenous corticosteroids on the day PD-(L)1 blockade was started. Use of corticosteroids within 30 days of the start of PD-(L)1 blockade was also collected for the MSKCC cohort. Information about the type of corticosteroid, indication, and route of administration were collected. Dose of corticosteroids was expressed as total daily milligrams of prednisone equivalents. Clinicopathologic characteristics, including age, gender, histology, Eastern Cooperative Oncology Group performance status, and smoking history, were collected for all patients. Efficacy of PD-(L)1 blockade was determined by local specialized radiologists (C.C. at GRCC and N.L., A.P., and D.H. at MSKCC) using Response Evaluation Criteria in Solid Tumors (RECIST) version 1.1. All patients were observed until death or data lock-March 2017 for MSKCC and December 2017 for GRCC.

\section{Statistical Analysis}

Patient characteristics were described according to the status of corticosteroid use at baseline and compared with Fisher's exact test or $\chi^{2}$ test for categorical data. Progression-free survival (PFS) was defined as the time from ICB initiation to the first event (tumor progression or death from any cause); overall survival (OS) was defined as the time from ICB initiation to death from any cause. Patients with no event were censored at the date of last follow-up. Best overall response differences were analyzed using Fisher's exact test or $\chi^{2}$ test. Patients who died before radiologic assessment were categorized as nonresponders. Other patients who were not evaluable for response ( $\mathrm{n}=4$ in MSKCC cohort, none in GRCC cohort), were not included in objective response assessment but were included for PFS and OS. Survival curves were estimated using the Kaplan-Meier method and compared with the log-rank test (univariable analysis). Univariable hazard ratios (HRs) were calculated using the log-rank method. We used multivariable Cox proportional hazards regression model to determine HRs and 95\% CIs for PFS and OS and odds ratios for best overall response. The pooled cohort $(\mathrm{N}=640)$ was used in subgroup and multivariable analysis to increase power. Statistical tests were two sided, and $P$ values $<.05$ were considered statistically significant. Statistical analyses were carried out using $\mathrm{R}$ statistical software.

\section{RESULTS}

We identified 640 patients treated with PD-(L)1 blockade at MSKCC $(n=455)$ and GRCC $(n=185)$. At the time of ICB initiation, $90(14 \%)$ of the 640 patients received $\geq 10 \mathrm{mg}$ of prednisone equivalent-53 (12\%) of 455 patients in the MSKCC cohort and 37 (20\%) of 185 patients in the GRCC cohort. A small fraction of additional patients $(n=17 ; 3 \%)$ received $<10 \mathrm{mg}$ of prednisone equivalent at the initiation of ICB and were included in the noncorticosteroid group, as this low dose was considered to be in the range of physiologic adrenal replacement and is not typically excluded in clinical trials. The most common indications for corticosteroids were dyspnea or other respiratory symptoms (33\%), fatigue (21\%), and brain metastases (19\%; Appendix Table $\mathrm{A} 1$, online only). In each group, clinicopathologic characteristics were typical of patients with advanced NSCLC and were generally well balanced between those who did or did not receive corticosteroids, with the two expected exceptions; poor performance status and history of brain metastases were more common in those who received corticosteroids (Table 1).

In the MSKCC cohort, use of baseline corticosteroids of $\geq 10 \mathrm{mg}$ was associated with decreased overall response rate (ORR; $6 \% v 19 \% ; P=.02$; Fig 1A), shorter PFS (median, 1.9 months $v$ 2.6 months; HR, 1.7; $P=.001$; Fig 1B), and shorter OS (median, 5.4 months $v 12.1$ months; HR, $2.1 ; P<.001$; Fig $1 \mathrm{C}$ ). In the GRCC cohort, ORR was decreased but not significantly different in those who received baseline corticosteroids $\geq 10 \mathrm{mg}$ ( $8 \% v 18 \% ; P=.2$; Fig 1D), whereas PFS and OS were significantly shorter (PFS: median, 1.7 months $v 1.8$ months; HR, $1.5 ; P<.001$; Fig 1E; and OS: median, 3.3 months $v 9.4$ months; HR, 2.0; $P<.001$; Fig $1 \mathrm{~F})$.

In the pooled cohort of patients from both centers $(\mathrm{N}=640)$, baseline corticosteroids had a consistently negative effect on efficacy of PD-(L)1 blockade (Appendix Fig A1, online only), with diminished PFS and OS observed in nearly every subgroup examined (Fig 2).

Cognizant of the potential confounding effects of prognostic variables associated with corticosteroid use and other predictive features associated with response to $\mathrm{PD}(\mathrm{L})$-1 blockade, we performed a multivariable analysis in the pooled cohort $(\mathrm{N}=640)$, incorporating smoking history, performance status, and history of brain metastases. Corticosteroid use ( $\geq 10 \mathrm{mg} v<10 \mathrm{mg}$ ) at the time of the initiation of PD-(L) 1 blockade remained associated with decreased ORR (odds ratio, $0.42 ; P=.053$ ) and significantly shorter PFS (HR, 1.31; $P=.03$ ) and OS (HR, 1.66; $P<.001$; Table 2).

We also examined the effect of corticosteroid dose and timing on efficacy. In the pooled cohort from both centers, there was a similar detriment in efficacy when examining $>20 \mathrm{mg}$ of prednisone or $10 \mathrm{mg}$ to $19 \mathrm{mg}$ compared with patients who received $<10 \mathrm{mg}$ of corticosteroids (Appendix Fig A2, online only). In the MSKCC cohort (data not available from GRCC cohort), patients who received and discontinued corticosteroids days 1 to 30 before to the initiation of PD-(L)1 (66 of 455 patients) had intermediate PFS and OS compared with those who received corticosteroids on the day of ICB initiation (53 of 455 patients) and those who received no corticosteroids within 30 days of the start of therapy (Appendix Fig A3, online only). 


\begin{tabular}{|c|c|c|c|c|c|c|}
\hline \multirow[b]{2}{*}{ Baseline Characteristic } & \multicolumn{3}{|c|}{ MSKCC } & \multicolumn{3}{|c|}{ GRCC } \\
\hline & $\begin{array}{l}\text { Prednisone } \geq 10 \mathrm{mg} \\
\qquad(\mathrm{n}=53)\end{array}$ & $\begin{array}{l}\text { Prednisone }<10 \mathrm{mg} \\
\qquad(n=402)\end{array}$ & $P$ & $\begin{array}{l}\text { Prednisone } \geq 10 \mathrm{mg} \\
\qquad(\mathrm{n}=37)\end{array}$ & $\begin{array}{c}\text { Prednisone }<10 \mathrm{mg} \\
\quad(\mathrm{n}=148)\end{array}$ & $P$ \\
\hline \multicolumn{7}{|l|}{ Age, years } \\
\hline$\geq 65$ & $60(32)$ & $55(221)$ & .55 & $35(13)$ & $39(57)$ & .9 \\
\hline$<65$ & $40(21)$ & $45(181)$ & & $65(24)$ & $61(91)$ & \\
\hline \multicolumn{7}{|l|}{ Sex } \\
\hline Male & $49(26)$ & $48(194)$ & 1.0 & $70(26)$ & $65(96)$ & .6 \\
\hline Female & $51(27)$ & $52(208)$ & & $30(11)$ & $35(52)$ & \\
\hline \multicolumn{7}{|l|}{ ECOG performance status } \\
\hline $0-1$ & 70 (37) & 92 (369) & $<.01$ & $57(21)$ & $83(123)$ & $<.01$ \\
\hline$\geq 2$ & $30(16)$ & $8(33)$ & & $43(16)$ & $17(25)$ & \\
\hline \multicolumn{7}{|l|}{ Smoking status } \\
\hline Ever & $77(41)$ & $83(335)$ & .3 & $92(34)$ & 87 (129) & .8 \\
\hline Never & $22(12)$ & $17(67)$ & & $8(3)$ & $11(16)$ & \\
\hline \multicolumn{7}{|l|}{ Histology } \\
\hline Squamous & $15(8)$ & $18(72)$ & .7 & $24(9)$ & $28(40)$ & .8 \\
\hline Nonsquamous & $85(45)$ & $82(330)$ & & $76(28)$ & $73(108)$ & \\
\hline \multicolumn{7}{|l|}{ EGFR mutation status } \\
\hline EGFR mutant & $11(6)$ & $8(32)$ & .4 & $5(2)$ & $5(7)$ & .7 \\
\hline EGFR wild type & $77(41)$ & 83 (333) & & $62(23)$ & $70(104)$ & \\
\hline EGFR unknown & $11(6)$ & $9(37)$ & & $32(12)$ & $25(37)$ & \\
\hline \multicolumn{7}{|l|}{ Line of therapy } \\
\hline First or second line & $56(30)$ & 67 (268) & .2 & $38(14)$ & $52(78)$ & .1 \\
\hline Third line or later & $46(23)$ & 33 (134) & & $62(23)$ & $47(70)$ & \\
\hline \multicolumn{7}{|l|}{ History of brain metastases } \\
\hline Yes & $42(22)$ & $23(94)$ & $<.01$ & $51(19)$ & $13(19)$ & $<.01$ \\
\hline No & $58(31)$ & 77 (308) & & $49(18)$ & 87 (129) & \\
\hline $\begin{array}{l}\text { NOTE. Data are given as } \\
\text { Abbreviations: ECOG, East } \\
\text { Kettering Cancer Center. }\end{array}$ & perative Oncology Grou & EFR, epidermal growth & recep & RCC, Gustave Roussy & er Center; MSKCC, M & al Sloan \\
\hline
\end{tabular}

Six patients (MSKCC $[\mathrm{n}=3]$, GRCC $[\mathrm{n}=3]$ ) experienced a partial response to $\mathrm{PD}-(\mathrm{L}) 1$ blockade despite the use of corticosteroids at the time of treatment initiation (Appendix Table A2, online only). These patients received $10 \mathrm{mg}$ to $20 \mathrm{mg}$ of corticosteroids for palliative indications, such as fatigue, respiratory symptoms, and pain. There were no evident differences in the clinical features of patients who experienced responses; all responders had an Eastern Cooperative Oncology Group performance status of 1 . Four of six patients had continued response to therapy for more than 15 months, although the responses of two patients were more limited, including one patient whose response lasted for only 2.4 months and was followed by rapid clinical deterioration and death as a result of progressive disease.

\section{DISCUSSION}

We report that the use of corticosteroids at the start of PD-(L)1 blockade is associated with inferior outcomes in two independent cohorts. This analysis of 640 patients from two institutions evaluated a patient population that was largely excluded from clinical trials that evaluated PD-(L)1 blockade such that this can only be addressed with real-world data.

Corticosteroids, specifically systemic adrenal glucocorticoids, play a critical physiologic role in feedback inhibition of inflammatory responses and immune system homeostasis and have long been used for their immunosuppressive properties. These effects can offer significant benefit in the treatment of autoimmune diseases, but may have unintended consequences in patients with cancer. Exogenous dexamethasone has been demonstrated to suppress IL-2-mediated activation of effector T cells ${ }^{16}$ and increase immunosuppressive regulatory T cells. ${ }^{17,18}$

Corticosteroids are the mainstay for the treatment of immune-related adverse events in patients who receive ICB therapy, and fortunately the use of corticosteroids in patients with melanoma ${ }^{13,14}$ and NSCLC $^{12}$ (and other immune modulating medications, such as infliximab) in this context has not been associated with decreased efficacy of ICB. Still, it is possible that treatment with corticosteroids immediately before the initiation of PD-(L)1 blockade could distinctly affect efficacy, perhaps by blunting a proliferative burst of CD8-positive T cells needed in response to $\mathrm{PD}-(\mathrm{L}) 1$ blockade. ${ }^{19}$

Corticosteroids are an important and common treatment of a variety of symptoms in patients with cancer, particularly NSCLC. Corticosteroids may be required for the control of brain metastasis and can improve symptoms of fatigue, dyspnea, ${ }^{9}$ and anorexia. On the basis of these data, in patients for whom treatment with $\mathrm{PD}-(\mathrm{L}) 1$ blockade is planned, it may be prudent to attempt to manage these symptoms with other pharmacologic ${ }^{9,20,21}$ and/or nonpharmacologic ${ }^{8,22}$ methods. These strategies could enable patients to be tapered off corticosteroids before the start of PD-(L)1 blockade to potentially achieve maximum benefit from these agents; however, of importance, medically necessary corticosteroids (eg, management of brain metastases) should not be avoided.

This work has focused on patients who were treated with single-agent PD-(L)1 inhibitor. Of note, regimens that combine 
A

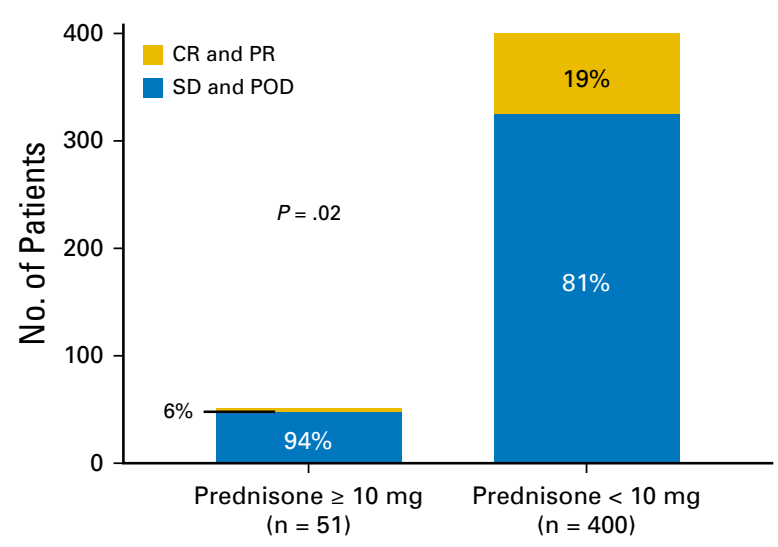

B

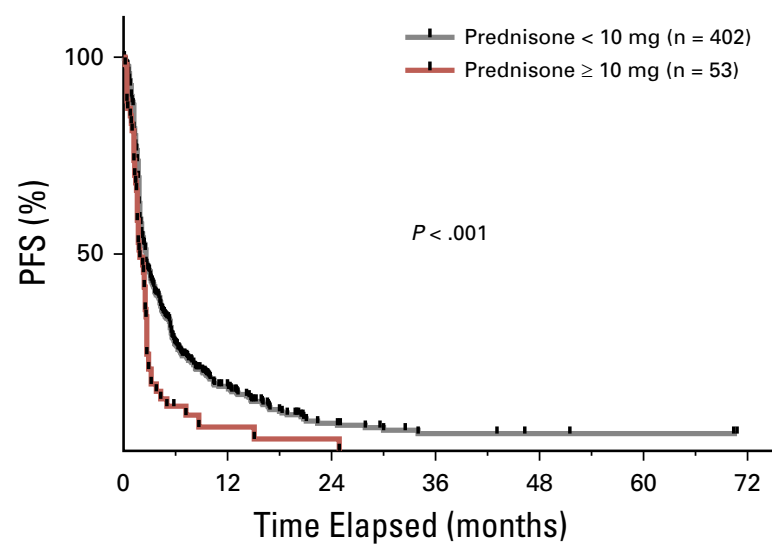

No. at risk:

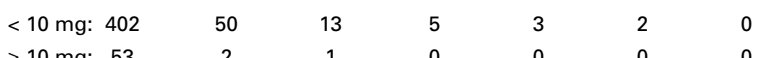

C

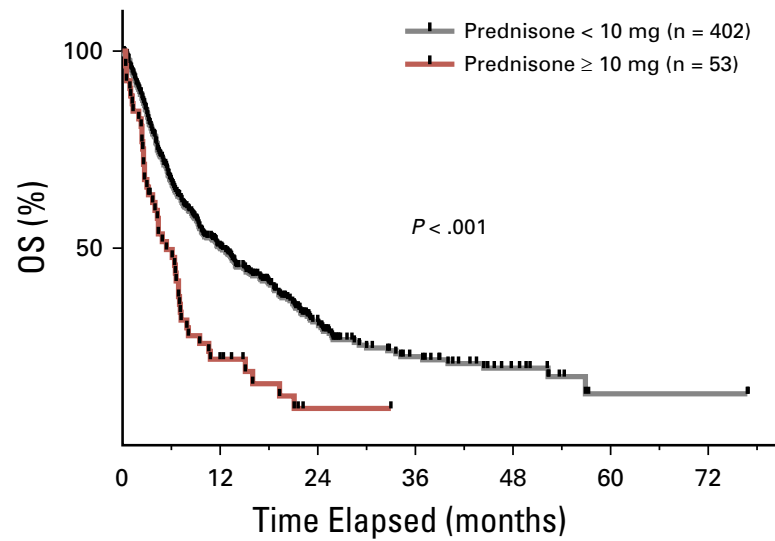

No. at risk:

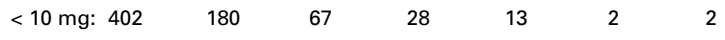

$\geq 10 \mathrm{mg}: 53$

11
D

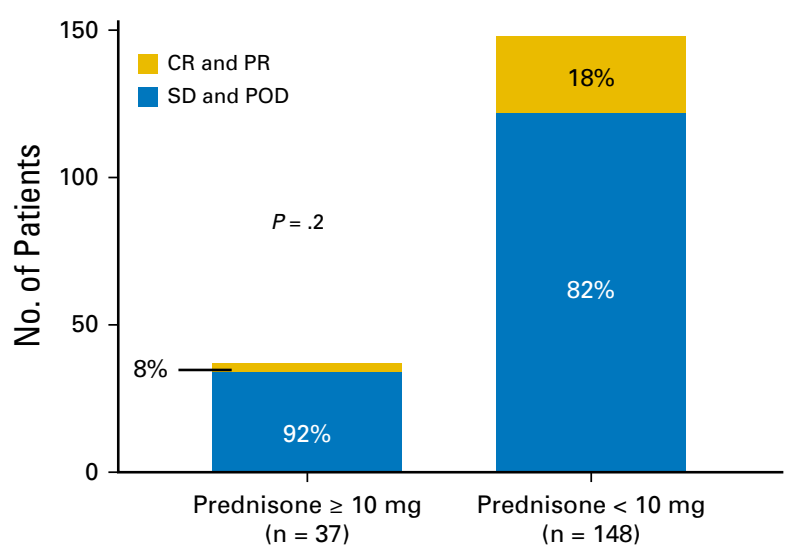

E

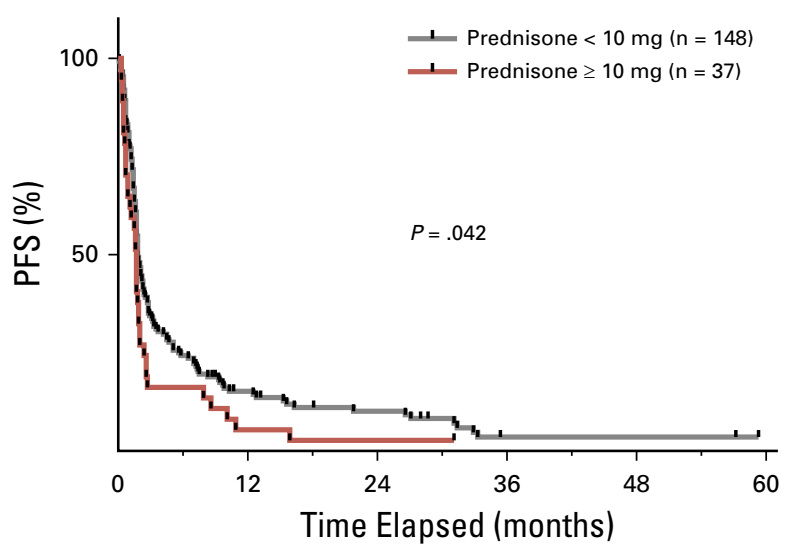

No. at risk:

\begin{tabular}{|c|c|c|c|c|}
\hline < 10 mg: 148 & 19 & 11 & 2 & 2 \\
\hline$\geq 10 \mathrm{mg}: 37$ & 2 & 1 & 0 & 0 \\
\hline
\end{tabular}

\section{$\mathbf{F}$}

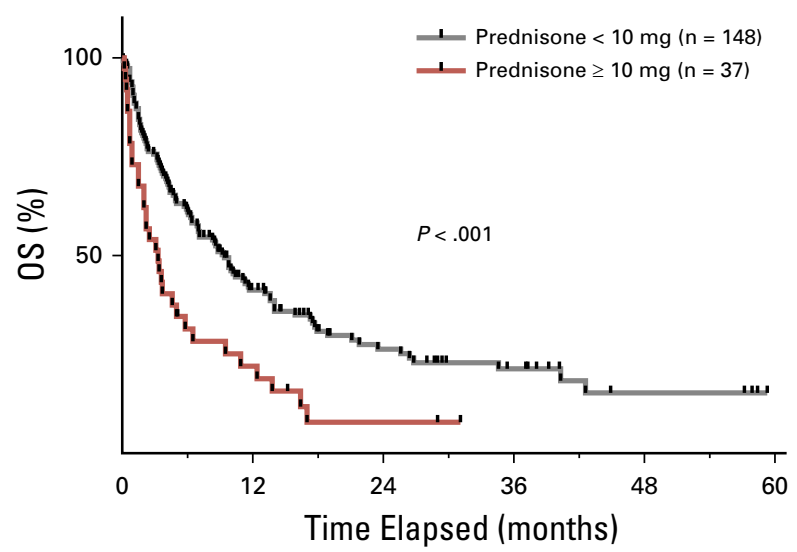

No. at risk:

$\begin{array}{ccccccc}<10 \mathrm{mg}: & 148 & 49 & 23 & 12 & 4 & 0 \\ \geq 10 \mathrm{mg}: & 37 & 7 & 2 & 0 & 0 & 0\end{array}$

Fig 1. Response rates ( $A$ and D), progression-free survival (PFS; $B$ and $E$ ), and overall survival (OS; $C$ and $E$ ) of patients treated with programmed death-ligand 1 blockade

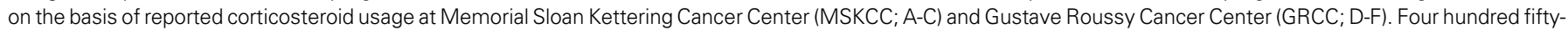

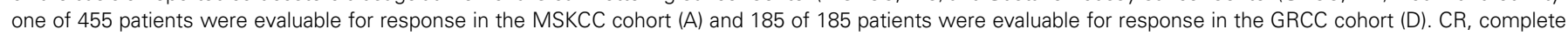
response; $\mathrm{POD}$, progression of disease; $\mathrm{PR}$, partial response; $\mathrm{SD}$, stable disease. 


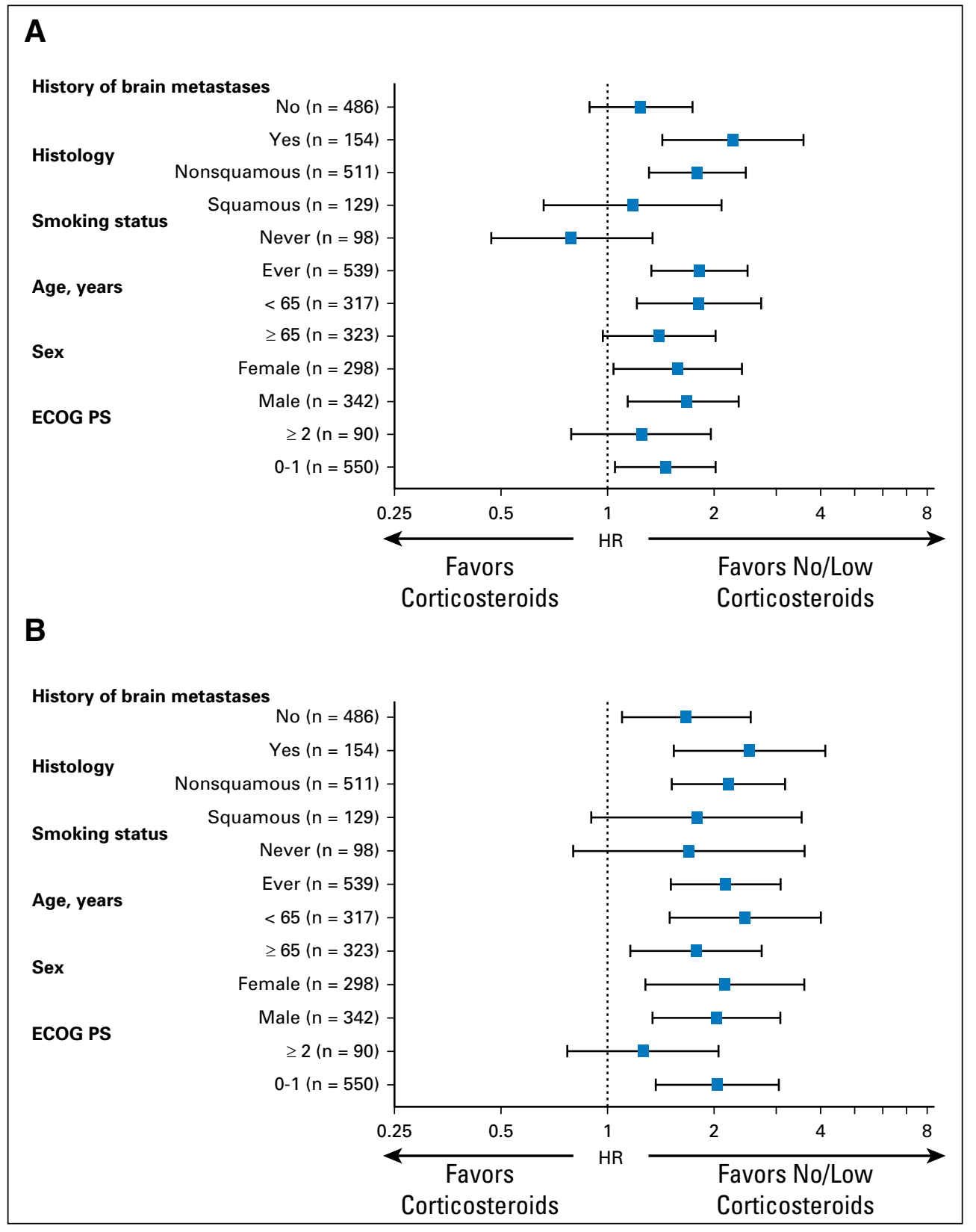

Fig 2. Forest plot of subgroup analyses of independent prognostic factors for (A) progression-free survival and (B) overall survival in the pooled cohort (Memorial Sloan Kettering Cancer Center and Gustave Roussy Cancer Center combined). ECOG, Eastern Cooperative Oncology Group; HR, hazard ratio; PS, performance status.

chemotherapy and PD-(L) 1 blockade ${ }^{23}$ are emerging with promising efficacy, despite the routine use of corticosteroids as a supportive medication for the prevention of rash, nausea, and potential hypersensitivity reactions. It is possible that transient corticosteroids given along with chemotherapy and PD-(L)1 blockade are not deleterious in the same way as more chronically administered corticosteroids leading up to PD-(L)1 blockade. Alternatively, the efficacy of these regimens despite corticosteroid administration could be a signal of synergy between chemotherapy and ICB, overcoming the otherwise deleterious effects of concurrent steroids. It will be interesting to examine the outcomes of chemotherapy plus $\mathrm{PD}(\mathrm{L})-1$ combinations that minimize corticosteroid use-for example, use of abraxane in the IMpower130 (ClinicalTrial.gov identifier: NCT 02367794) ${ }^{24}$ and KEYNOTE407 (ClinicalTrials.gov identifier: NCT 02775435) ${ }^{25}$ studies.
Although data on the effects of baseline corticosteroids is only possible through such real-world studies as this, there are important limitations. Although outcomes were assessed retrospectively, objective response was determined by direct review of scans by radiologists and quantified by RECIST. The overall sample size is large $(\mathrm{N}=640)$, but only a modest number of patients received corticosteroids of any dose at the time of ICB initiation $(n=107)$, which may reflect the caution of clinical providers in administering corticosteroids to patients being treated with ICB. A pooled analysis of both independent cohorts was used in subgroup and multivariable analyses to increase power; however, this sample size limited the comprehensive exploration of varying cut points of dose or timing of corticosteroids associated with distinctly inferior outcomes. The prednisone threshold of $10 \mathrm{mg}$ was chosen here as it is typically applied as an exclusion in clinical trials, and we found 
Table 2. Multivariable Analysis of Best Overall Response Rate, Progression-Free Survival, and Overall Survival in a Pooled Cohort of Patients: Memorial Sloan Kettering Cancer Center and Gustave Roussy Cancer Center Combined

\begin{tabular}{|c|c|c|c|c|c|c|}
\hline \multirow[b]{2}{*}{ Patient Characteristic } & \multicolumn{2}{|c|}{ Best Overall Response } & \multicolumn{2}{|c|}{ Progression-Free Survival } & \multicolumn{2}{|c|}{ Overall Survival } \\
\hline & $\begin{array}{l}\text { Odds Ratio } \\
\text { (95\% Cl) }\end{array}$ & $P$ & $\begin{array}{l}\text { Hazard Ratio } \\
(95 \% \mathrm{Cl})\end{array}$ & $P$ & $\begin{array}{c}\text { Hazard Ratio } \\
(95 \% \mathrm{Cl})\end{array}$ & $P$ \\
\hline Smoking status (never $v$ ever) & $0.33(0.15$ to 0.74$)$ & .007 & 1.64 (1.30 to 2.04$)$ & $<.001$ & $1.03(0.81$ to 1.33$)$ & .78 \\
\hline ECOG performance status ( $\geq 2 \vee 0-1)$ & $0.29(0.11$ to 0.75$)$ & .11 & $1.97(1.55$ to 2.50$)$ & $<.001$ & 2.29 (1.75 to 2.98$)$ & $<.001$ \\
\hline History of brain metastases (yes $v$ no) & 0.88 (0.52 to 1.49$)$ & .6 & $1.16(0.96$ to 1.41$)$ & .1 & 1.37 (1.11 to 1.7$)$ & .003 \\
\hline Corticosteroid use ( $\geq 10 \mathrm{mg} v<10 \mathrm{mg}$ ) & $0.42(0.17$ to 1.01$)$ & .053 & $1.31(1.03$ to 1.67$)$ & .03 & 1.66 (1.28 to 2.16$)$ & $<.001$ \\
\hline
\end{tabular}

Abbreviation: ECOG, Eastern Cooperative Oncology Group.

similar detrimental effects in patients who received $10 \mathrm{mg}$ to $19 \mathrm{mg}$ daily versus $\geq 20 \mathrm{mg}$ of prednisone.

An additional limitation of this work is distinguishing between the prognostic and predictive effects of corticosteroids in patients who receive ICB. Use of corticosteroids may simply identify patients with aggressive disease and greater symptom burden necessitating their use. Given the persistent deleterious effect of corticosteroids in both the subgroup and multivariable analyses, we propose that baseline corticosteroids have a predictive effect, but we do not have functional or mechanistic data to prove this with certainty. In addition, data on the known predictive biomarkers, such as PD-L1 staining and tumor mutational burden, were not available in the majority of patients in this analysis and so could not be included here. We propose that baseline corticosteroid use should be incorporated in future data analyses to further optimize predictive models of $\mathrm{PD}-(\mathrm{L}) 1$ efficacy. Ultimately, whether baseline corticosteroids represent correlation or causation, it is clinically relevant for both patients and providers to recognize the effect of corticosteroids on ICB efficacy in patients with NSCLC.

Treatment with PD-(L)1 blockade has been a significant advance for patients with NSCLC and other malignancies. As these agents have become a standard of care, it is imperative that we recognize and inform common practices that may affect the efficacy of these agents. The administration of corticosteroids for a variety of indications, from decreased appetite and fatigue to symptomatic brain metastases, is one such common practice. We have demonstrated that the use of corticosteroids at the time of the initiation of PD-(L)1 blockade is associated with diminished efficacy of ICB. Prudent use of corticosteroids at the time of initiating PD-(L)1 blockade is warranted.

\section{AUTHORS' DISCLOSURES OF POTENTIAL CONFLICTS OF INTEREST}

Disclosures provided by the authors are available with this article at jco.org.

\section{AUTHOR CONTRIBUTIONS}

Conception and design: Kathryn C. Arbour, Laura Mezquita, Hira Rizvi, Gregory J. Riely, Benjamin Besse, Matthew D. Hellmann

Financial support: Matthew D. Hellmann

Provision of study materials or patients: Benjamin Besse, Matthew D. Hellmann

Collection and assembly of data: Kathryn C. Arbour, Laura Mezquita, Niamh Long, Hira Rizvi, Edouard Auclin, Gala Martínez-Bernal, Roberto Ferrara, W. Victoria Lai, Lizza E.L. Hendriks, Caroline Caramella, Andrew J. Plodkowski, Darragh Halpenny, Benjamin Besse, Matthew D. Hellmann Data analysis and interpretation: Kathryn C. Arbour, Laura Mezquita, Niamh Long, Andy Ni, Lizza E.L. Hendriks, Joshua K. Sabari, Jamie E. Chaft, David Planchard, Gregory J. Riely, Benjamin Besse, Matthew D. Hellmann

Manuscript writing: All authors

Final approval of manuscript: All authors

Accountable for all aspects of the work: All authors

\section{REFERENCES}

1. Le DT, Uram JN, Wang H, et al: PD-1 blockade in tumors with mismatch-repair deficiency. $\mathrm{N}$ Engl $\mathrm{J}$ Med 372:2509-2520, 2015

2. Borghaei H, Paz-Ares L, Horn L, et al: Nivolumab versus docetaxel in advanced nonsquamous non-small-cell lung cancer. N Engl J Med 373: 1627-1639, 2015

3. Reck $M$, Rodríguez-Abreu $D$, Robinson $A G$, et al: Pembrolizumab versus chemotherapy for PDL1-positive non-small-cell lung cancer. N Engl J Med 375:1823-1833, 2016

4. Rittmeyer A, Barlesi F, Waterkamp D, et al: Atezolizumab versus docetaxel in patients with previously treated non-small-cell lung cancer (OAK): A phase 3, open-label, multicentre randomised controlled trial. Lancet 389:255-265, 2017
5. Ryken TC, McDermott $M$, Robinson PD, et al: The role of steroids in the management of brain metastases: A systematic review and evidencebased clinical practice guideline. J Neurooncol 96: 103-114, 2010

6. Paulsen O, Klepstad P, Rosland JH, et al: Efficacy of methylprednisolone on pain, fatigue, and appetite loss in patients with advanced cancer using opioids: A randomized, placebo-controlled, doubleblind trial. J Clin Oncol 32:3221-3228, 2014

7. Yennurajalingam $S$, Frisbee-Hume $S$, Palmer $\mathrm{JL}$, et al: Reduction of cancer-related fatigue with dexamethasone: A double-blind, randomized, placebocontrolled trial in patients with advanced cancer. J Clin Oncol 31:3076-3082, 2013

8. Ben-Aharon I, Gafter-Gvili $A$, Paul $M$, et al: Interventions for alleviating cancer-related dyspnea: A systematic review. J Clin Oncol 26:2396-2404, 2008
9. Lin RJ, Adelman RD, Mehta SS: Dyspnea in palliative care: Expanding the role of corticosteroids. J Palliat Med 15:834-837, 2012

10. Libert C, Dejager L: How steroids steer T cells. Cell Reports 7:938-939, 2014

11. Postow MA, Sidlow $R$, Hellmann MD: Immune-related adverse events associated with immune checkpoint blockade. N Engl J Med 378: 158-168, 2018

12. Santini $F C$, Rizvi $H$, Wilkins $O$, et al: Safety of retreatment with immunotherapy after immunerelated toxicity in patients with lung cancers treated with anti-PD(L)-1 therapy. J Clin Oncol 35:9012, 2017 (suppl)

13. Horvat TZ, Adel NG, Dang T-O, et al: Immunerelated adverse events, need for systemic immunosuppression, and effects on survival and time to treatment failure in patients with melanoma treated 
with ipilimumab at Memorial Sloan Kettering Cancer Center. J Clin Oncol 33:3193-3198, 2015

14. Weber JS, Larkin JMG, Schadendorf D, et al: Management of gastrointestinal (GI) toxicity associated with nivolumab (NIVO) plus ipilimumab (IPI) or IPI alone in phase II and III trials in advanced melanoma (MEL). J Clin Oncol 35:9523, 2017 (suppl)

15. Schadendorf D, Wolchok JD, Hodi FS, et al: Efficacy and safety outcomes in patients with advanced melanoma who discontinued treatment with nivolumab and ipilimumab because of adverse events: A pooled analysis of randomized phase II and III trials. J Clin Oncol 35:3807-3814, 2017

16. Bianchi M, Meng C, Ivashkiv LB: Inhibition of IL-2-induced Jak-STAT signaling by glucocorticoids. Proc Natl Acad Sci USA 97:9573-9578, 2000

17. Chen $X$, Murakami $T$, Oppenheim JJ, et al: Differential response of murine $\mathrm{CD} 4^{+} \mathrm{CD} 25^{+}$and CD $4^{+} \mathrm{CD} 25^{-} \mathrm{T}$ cells to dexamethasone-induced cell death. Eur J Immunol 34:859-869, 2004
18. Chen X, Oppenheim JJ, Winkler-Pickett RT, et al: Glucocorticoid amplifies IL-2-dependent expansion of functional FoxP $3{ }^{+} \mathrm{CD} 4{ }^{+} \mathrm{CD} 25^{+} \mathrm{T}$ regulatory cells in vivo and enhances their capacity to suppress EAE. Eur J Immunol 36:2139-2149, 2006

19. Im SJ, Hashimoto $M$, Gerner $M Y$, et al: Defining $\mathrm{CD}^{+} \mathrm{T}$ cells that provide the proliferative burst after PD-1 therapy. Nature 537:417-421, 2016

20. Minton O, Richardson A, Sharpe $M$, et al: $A$ systematic review and meta-analysis of the pharmacological treatment of cancer-related fatigue. J Natl Cancer Inst 100:1155-1166, 2008

21. Minton O, Richardson A, Sharpe M, et al: Drug therapy for the management of cancer-related fatigue. Cochrane Database Syst Rev 2010:CD006704، 2010

22. Greer JA, MacDonald JJ, Vaughn J, et al: Pilot study of a brief behavioral intervention for dyspnea in patients with advanced lung cancer. J Pain Symptom Manage 50:854-860, 2015

23. Langer CJ, Gadgeel SM, Borghaei $H$, et al: Carboplatin and pemetrexed with or without pembrolizumab for advanced, non-squamous non-smallcell lung cancer: A randomised, phase 2 cohort of the open-label KEYNOTE-021 study. Lancet Oncol 17: 1497-1508, 2016

24. Jotte RM, Capuzzo F, Vynnychenko I, et al: IMpower131: Primary PFS and safety analysis of a randomized phase III study of atezolizumab + carboplatin + paclitaxel or nab-paclitaxel vs carboplatin + nab-paclitaxel as $1 \mathrm{~L}$ therapy in advanced squamous NSCLC. J Clin Oncol 36, 2018 (suppl; abstr LBA9000)

25. Paz-Aras LG, Luft A, Tafreshi A, et al: Phase 3 study of carboplatin-paclitaxel/nab-paclitaxel (Chemo) with or without pembrolizumab (Pembro) for patients (Pts) with metastatic squamous (Sq) non-small cell lung cancer (NSCLC). J Clin Oncol 36, 2018 (suppl; abstr 105)

\section{Affiliations}

Matthew D. Hellmann, Parker Institute for Cancer Immunotherapy; Kathryn C. Arbour, Niamh Long, Hira Rizvi, Andy Ni, W. Victoria Lai, Joshua K. Sabari, Andrew J. Plodkowski, Darragh Halpenny, Jamie E. Chaft, Gregory J. Riely, and Matthew D. Hellmann, Memorial Sloan Kettering Cancer Center; Kathryn C. Arbour, W. Victoria Lai, Joshua K. Sabari, Jamie E. Chaft, Gregory J. Riely, and Matthew D. Hellmann, Weill Cornell Medical College, New York, NY; Laura Mezquita, Roberto Ferrara, Lizza E.L. Hendriks, Caroline Caramella, Benjamin Besse, and David Planchard, Gustave Roussy Cancer Center, Villejuif; Edouard Auclin, Hôpital Européen Georges Pompidou; Benjamin Besse, Paris-Sud University, Le Kremlin Bicêtre, Paris, France; Gala Martínez-Bernal, Virgen del Rocío Hospital, Seville, Spain; Lizza E.L. Hendriks, Maastricht University Medical Center, Maastricht, the Netherlands. 


\section{AUTHORS' DISCLOSURES OF POTENTIAL CONFLICTS OF INTEREST}

Impact of Baseline Steroids on Efficacy of Programmed Cell Death-1 and Programmed Death-Ligand 1 Blockade in Patients With Non-Small-Cell Lung Cancer

The following represents disclosure information provided by authors of this manuscript. All relationships are considered compensated. Relationships are self-held unless noted. I = Immediate Family Member, Inst = My Institution. Relationships may not relate to the subject matter of this manuscript. For more information about ASCO's conflict of interest policy, please refer to www.asco.org/rwc or ascopubs.org/jco/site/ifc.

\section{Kathryn C. Arbour}

No relationship to disclose

\section{Laura Mezquita}

No relationship to disclose

Niamh Long

No relationship to disclose

Hira Rizvi

No relationship to disclose

\section{Edouard Auclin}

No relationship to disclose

\section{Andy Ni}

No relationship to disclose

\section{Gala Martínez-Bernal}

Employment: Amgen, Janssen Pharmaceuticals

Honoraria: Amgen, Janssen Pharmaceuticals

Speakers' Bureau: Amgen, Janssen Pharmaceuticals

\section{Roberto Ferrara}

No relationship to disclose

\section{W. Victoria Lai}

No relationship to disclose

\section{Lizza E.L. Hendriks}

Consulting or Advisory Role: Bristol-Myers Squibb, Bristol-Myers Squibb (Inst), Boehringer Ingelheim (Inst)

Research Funding: Roche (Inst), Boehringer Ingelheim (Inst)

Travel, Accommodations, Expenses: Amgen, Roche, Bristol-Myers Squibb

\section{Joshua K. Sabari}

No relationship to disclose

\section{Caroline Caramella}

Consulting or Advisory Role: Bristol-Myers Squibb, Pfizer

\section{Andrew J. Plodkowski}

No relationship to disclose

\section{Darragh Halpenny}

No relationship to disclose

Jamie E. Chaft

Consulting or Advisory Role: Genentech, AstraZeneca, MedImmune, Merck, Bristol-Myers Squibb

Research Funding: Genentech (Inst), Bristol-Myers Squibb (Inst), AstraZeneca (Inst), MedImmune (Inst)

David Planchard

Consulting or Advisory Role: AstraZeneca, Boehringer Ingelheim, Bristol-Myers Squibb, Novartis, Roche, Pfizer, MSD Oncology, Celgene

\section{Gregory J. Riely}

Research Funding: Novartis (Inst), Genentech (Inst), Millennium Pharmaceuticals (Inst), GlaxoSmithKline (Inst), Pfizer (Inst), Infinity Pharmaceuticals (Inst), Ariad Pharmaceuticals (Inst)

Patents, Royalties, Other Intellectual Property: Patent application submitted covering pulsatile use of erlotinib to treat or prevent brain metastases (Inst)

Travel, Accommodations, Expenses: Merck Sharp \& Dohme

\section{Benjamin Besse}

Research Funding: AstraZeneca (Inst), Genentech (Inst), Pfizer (Inst), Boehringer Ingelheim (Inst), Eli Lilly (Inst), Servier (Inst), Onxeo (Inst), Bristol-Myers Squibb (Inst), Ose Pharma (Inst), Inivata (Inst), Novartis (Inst), OncoMed (Inst), Loxo (Inst)

Travel, Accommodations, Expenses: Roche, Pfizer, Bristol-Myers Squibb, Medarex, Novartis, Pierre Fabre

\section{Matthew D. Hellmann}

Consulting or Advisory Role: Bristol-Myers Squibb, Merck, Genentech, AstraZeneca, MedImmune, Janssen Pharmaceuticals, Mirati Therapeutics, Syndax, Shattuck Labs

Research Funding: Bristol-Myers Squibb 
A

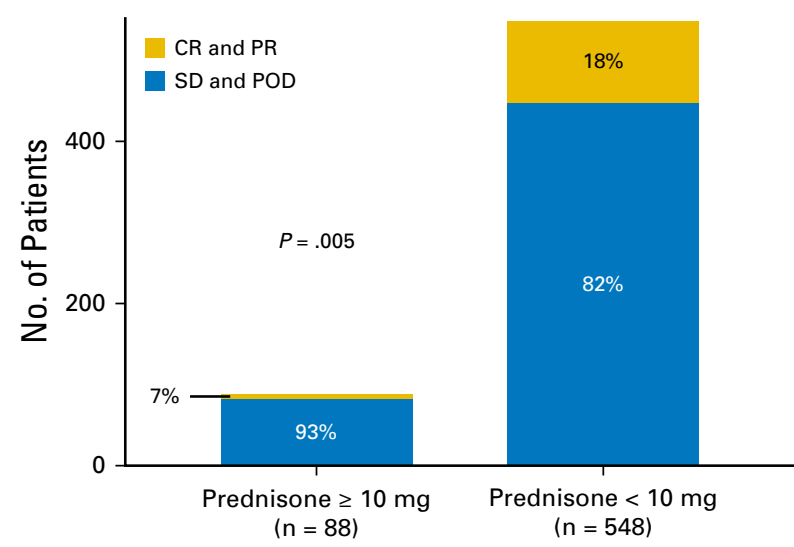

B

C
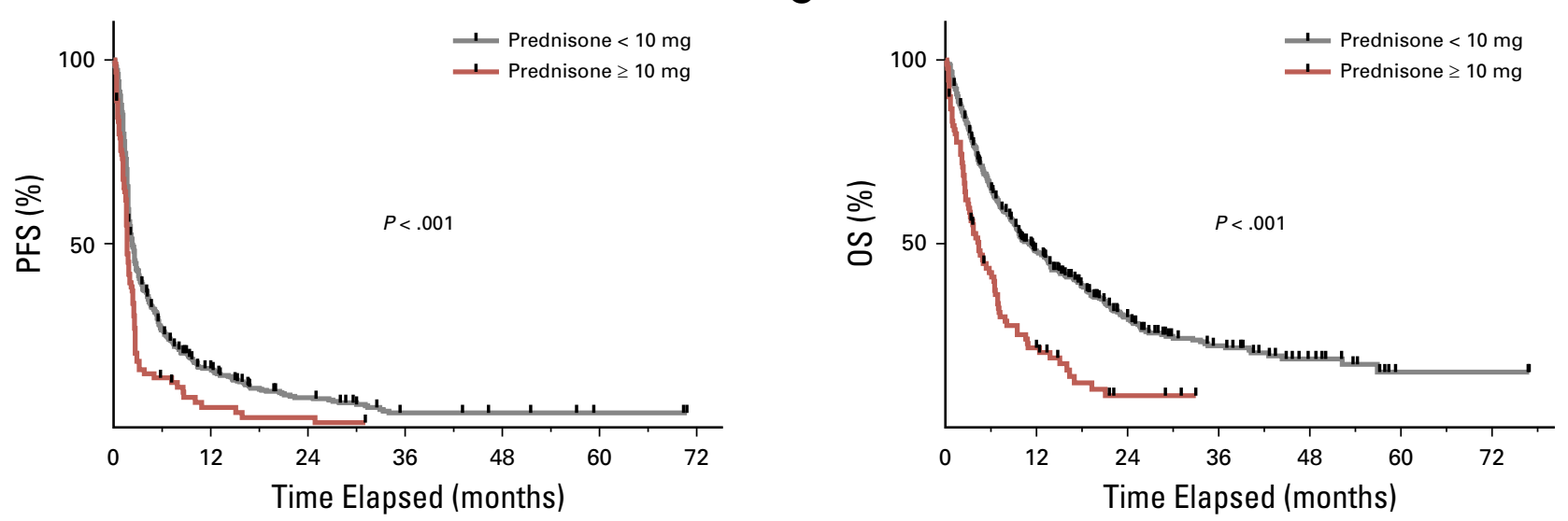

No. at risk:

$\begin{array}{cccccccc}<10 \mathrm{mg}: 550 & 69 & 24 & 7 & 5 & 2 & 0 \\ \geq 10 \mathrm{mg}: & 90 & 4 & 2 & 0 & 0 & 0 & 0\end{array}$

No. at risk:

\begin{tabular}{|c|c|c|c|c|c|}
\hline < $10 \mathrm{mg}: 550$ & 229 & 90 & 40 & 17 & 2 \\
\hline$\geq 10 \mathrm{mg}: 90$ & 18 & 3 & 0 & 0 & 0 \\
\hline
\end{tabular}

Fig A1. (A) Response rates of patients treated with programmed cell death-1 and programmed death-ligand 1 blockade according to different doses of corticosteroids in

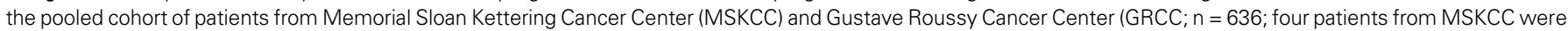

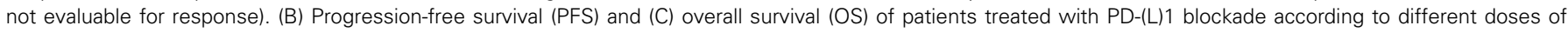

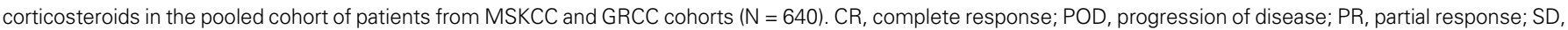
stable disease. 


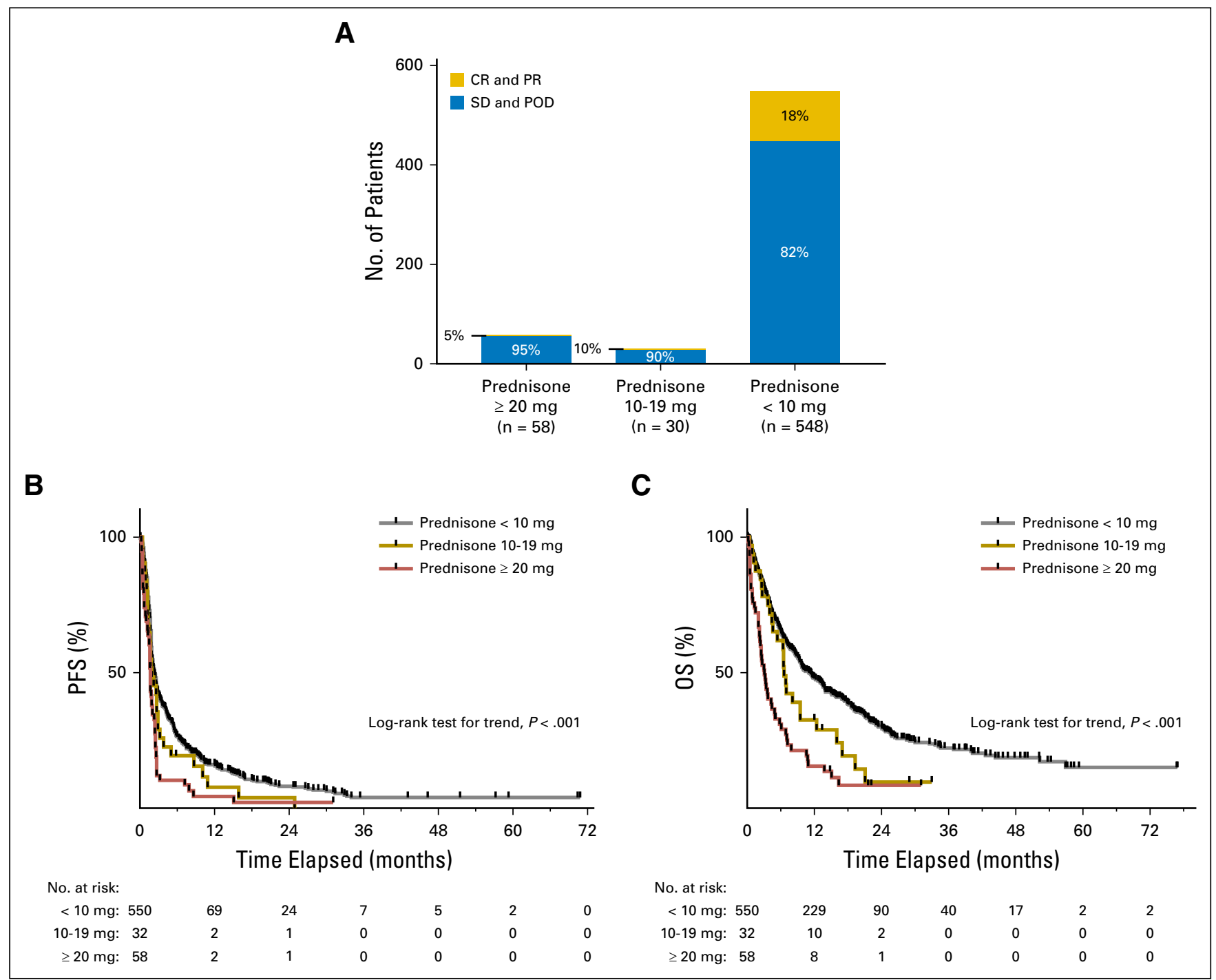

Fig A2. (A) Response rates of patients treated with programmed cell death-1 and programmed death-ligand 1 blockade according to different doses of corticosteroids in the pooled cohort of patients from Memorial Sloan Kettering Cancer Center (MSKCC) and Gustave Roussy Cancer Center (GRCC; $n=636$; four patients from MSKCC were not evaluable for response). (B) Progression-free survival (PFS) and (C) overall survival (OS) of patients treated with PD-(L)1 blockade according to different doses of corticosteroids in the pooled cohort of patients from MSKCC and GRCC cohorts ( $N=640)$. CR, complete response; POD, progression of disease; PR, partial response; SD, stable disease. 


\section{A}

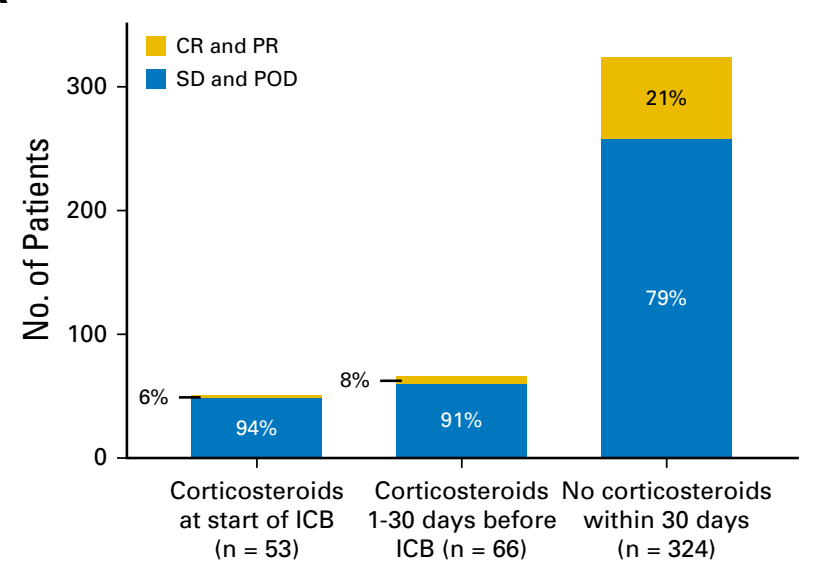

B

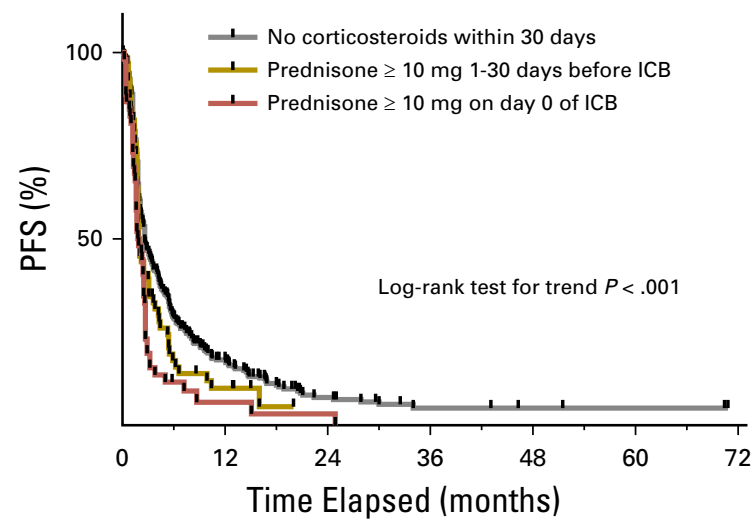

\section{C}

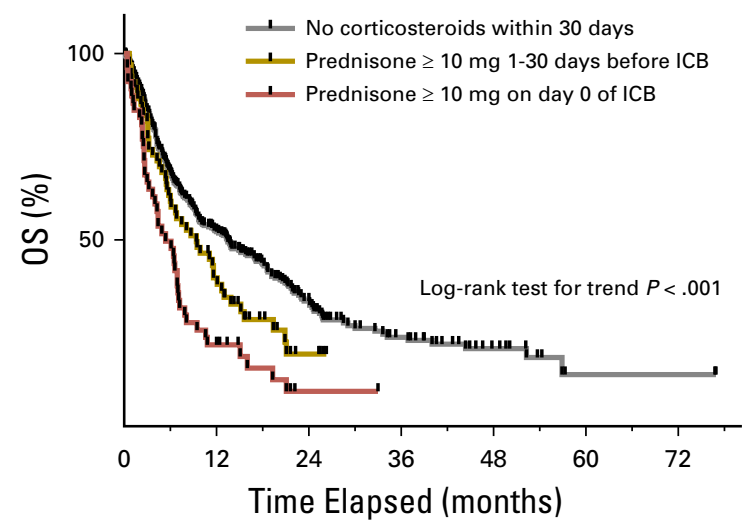

No. at risk:

\begin{tabular}{|c|c|c|c|c|c|c|c|c|c|c|c|c|c|}
\hline No corticosteroids: 336 & 45 & 13 & 5 & 3 & 2 & 0 & No corticosteroids: 336 & 157 & 63 & 28 & 13 & 2 & 2 \\
\hline$\geq 10 \mathrm{mg}$ ( $1-30$ days): 66 & 5 & 0 & 0 & 0 & 0 & 0 & $\geq 10 \mathrm{mg}$ ( $1-30$ days): 66 & 23 & 4 & 0 & 0 & 0 & 0 \\
\hline$\geq 10 \mathrm{mg}($ day 0$): 53$ & 2 & 1 & 0 & 0 & 0 & 0 & $\geq 10 \mathrm{mg}($ day 0$): 53$ & 11 & 1 & 0 & 0 & 0 & 0 \\
\hline
\end{tabular}

Fig A3. (A) Response rates ( $n=451$ ), (B) progression-free survival (PFS), and (C) overall survival (OS) of patients treated programmed cell death-1 and programmed death-

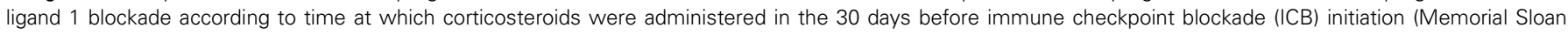
Kettering Cancer Center). CR, complete response; POD, progression of disease; PR, partial response; SD, stable disease. 


\begin{tabular}{|c|c|c|}
\hline Baseline Characteristic & $\begin{array}{c}\text { MSKCC } \\
(n=455)\end{array}$ & $\begin{array}{c}\text { GRCC } \\
(n=185)\end{array}$ \\
\hline Age, years, median (range) & 66 (31-93) & $61(29-84)$ \\
\hline Male & $48(220)$ & $66(122)$ \\
\hline Female & $52(235)$ & $44(63)$ \\
\hline \multicolumn{3}{|l|}{ ECOG performance status } \\
\hline$\geq 2$ & $11(49)$ & $22(41)$ \\
\hline \multicolumn{3}{|l|}{ Smoking status } \\
\hline Ever & 376 & $87(161)$ \\
\hline Never & 79 & $10(19)$ \\
\hline Pack-years, median (range) & $30(1-190)$ & $37(3-100)$ \\
\hline \multicolumn{3}{|l|}{ Histology } \\
\hline Adenocarcinoma & 76 (347) & $63(116)$ \\
\hline EGFR status unknown & $9(43)$ & $26(49)$ \\
\hline \multicolumn{3}{|c|}{ Daily dose of corticosteroids (prednisone or equivalent), mg } \\
\hline$\geq 20$ & $6(29)$ & $16(29)$ \\
\hline $10-19$ & $5(24)$ & $4(8)$ \\
\hline $1-9$ & $2(10)$ & $4(7)$ \\
\hline 0 & $86(392)$ & $76(141)$ \\
\hline $\begin{array}{l}\text { Median daily dose of corticosteroids (prednisone or } \\
\text { equivalent), mg (range) }\end{array}$ & $13(3-80)$ & $20(3-325)$ \\
\hline Indication for corticosteroid use $\geq 10 \mathrm{mg}$ & $(n=53)$ & $(n=37)$ \\
\hline Dyspnea & $30(15)$ & $41(15)$ \\
\hline Fatigue & $33(18)$ & $3(1)$ \\
\hline Brain metastases & $13(7)$ & $27(10)$ \\
\hline Pain & $9(5)$ & $11(6)$ \\
\hline
\end{tabular}

NOTE. Data are given as No. (\%), unless otherwise indicated.

Abbreviations: ECOG, Eastern Cooperative Oncology Group; EGFR, epidermal growth factor receptor; GRCC, Gustave Roussy Cancer Center; MSKCC, Memorial Sloan Kettering Cancer Center; NSCLC, non-small-cell lung cancer.

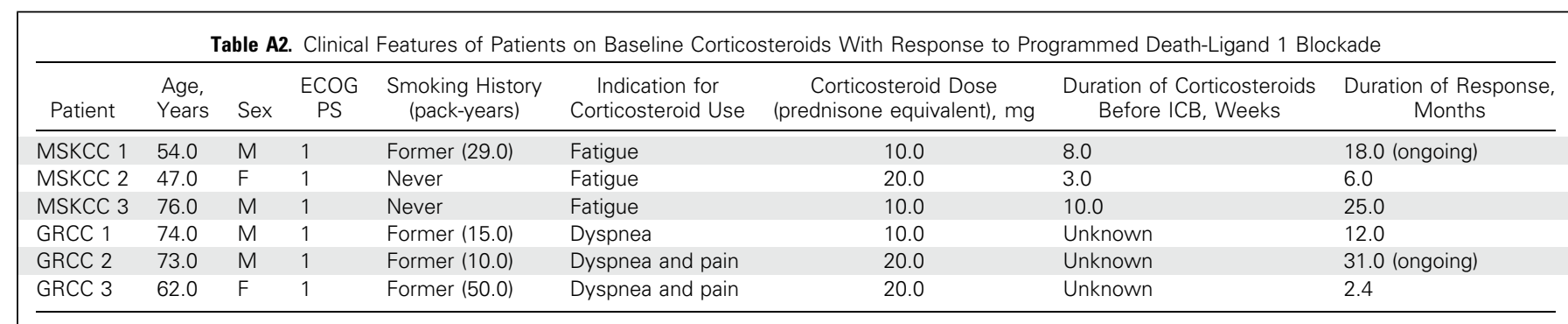

Abbreviations: ECOG, Eastern Cooperative Oncology Group; F, female; GRCC, Gustave Roussy Cancer Center; ICB, immune checkpoint blockade; M, male; MSKCC, Memorial Sloan Kettering Cancer Center; PS, performance status. 